\title{
An experimental study of the effect of different starting room temperatures on occupant comfort in Danish summer weather
}

\section{Bourdakis, Eleftherios; Simone, Angela; Olesen, Bjarne W.}

\section{Published in:}

Building and Environment

Link to article, DOI:

10.1016/j.buildenv.2018.03.046

Publication date:

2018

Document Version

Peer reviewed version

Link back to DTU Orbit

Citation (APA):

Bourdakis, E., Simone, A., \& Olesen, B. W. (2018). An experimental study of the effect of different starting room temperatures on occupant comfort in Danish summer weather. Building and Environment, 136, 269-278. https://doi.org/10.1016/j.buildenv.2018.03.046

\section{General rights}

Copyright and moral rights for the publications made accessible in the public portal are retained by the authors and/or other copyright owners and it is a condition of accessing publications that users recognise and abide by the legal requirements associated with these rights.

- Users may download and print one copy of any publication from the public portal for the purpose of private study or research.

- You may not further distribute the material or use it for any profit-making activity or commercial gain

- You may freely distribute the URL identifying the publication in the public portal 


\section{Accepted Manuscript}

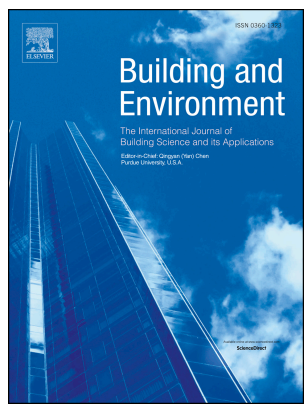

An experimental study of the effect of different starting room temperatures on occupant comfort in Danish summer weather

Eleftherios Bourdakis, Angela Simone, Bjarne W. Olesen

PII: $\quad$ S0360-1323(18)30181-1

DOI: $\quad$ 10.1016/j.buildenv.2018.03.046

Reference: $\quad$ BAE 5380

To appear in: Building and Environment

Received Date: 9 November 2017

Revised Date: 26 March 2018

Accepted Date: 27 March 2018

Please cite this article as: Bourdakis E, Simone A, Olesen BW, An experimental study of the effect of different starting room temperatures on occupant comfort in Danish summer weather, Building and Environment (2018), doi: 10.1016/j.buildenv.2018.03.046.

This is a PDF file of an unedited manuscript that has been accepted for publication. As a service to our customers we are providing this early version of the manuscript. The manuscript will undergo copyediting, typesetting, and review of the resulting proof before it is published in its final form. Please note that during the production process errors may be discovered which could affect the content, and all legal disclaimers that apply to the journal pertain. 
An experimental study of the effect of different starting room temperatures on occupant comfort in Danish summer weather

Eleftherios Bourdakis ${ }^{*}$, Angela Simone ${ }^{\mathrm{a}}$, Bjarne W. Olesen ${ }^{\mathrm{a}}$

${ }^{a}$ International Centre for Indoor Environment and Energy (ICIEE), Department of Civil

Engineering, Technical University of Denmark (DTU), Building 402, Kongens Lyngby, 2800, Denmark

\footnotetext{
* Corresponding author. Tel.: +32 (0) 484614737
}

E-mail address: elefbur@byg.dtu.dk 


\section{Abstract}

As office workers will usually have a slightly elevated metabolic rate when arriving at work, they may prefer a room temperature below the comfort range for sedentary activity in the morning. This possibility was studied in an experiment with 25 young people, male and female, exposed to four different conditions. Each condition consisted of two sessions, the simulated commute (activity equivalent to walking to work) and the office session. Each office session had a different starting room temperature, namely $18.5^{\circ} \mathrm{C}, 20^{\circ} \mathrm{C}, 21.5^{\circ} \mathrm{C}$ or $23^{\circ} \mathrm{C}$, followed by an increasing temperature "ramp" of $1.5 \mathrm{~K}$ every 30 minutes. During the last 30 minutes the temperature remained constant. Physical measurements were continuously recorded and subjective evaluation questionnaires were completed every 30 minutes. It was observed that, upon arrival at the office-lab, a room temperature of $20^{\circ} \mathrm{C}$ provided a thermal environment with neutral thermal sensation (0.23), low thermal dissatisfaction (8.6\%) and a high level of thermal comfort for the whole body (3.3). It was concluded that, in the cooling season, to improve the thermal sensation of occupants, a lower temperature than is suggested by the existing standards should be maintained in the early office hours, and that this will lead to a lower maximum room temperature during the day, which would result in less demand for cooling during the summer period.

\section{Keywords}

Whole-body thermal sensation; Thermal comfort; Sick building syndrome symptoms; Human subject experiment; Metabolic rate

\section{Introduction}

According to ISO Standard 7730 [1], thermal comfort is "the condition of mind that expresses satisfaction with the thermal environment". Warm or cold discomfort of the whole body, or unwanted heating or cooling of a human body part, can cause dissatisfaction and lead to thermal conditions being judged unacceptable. Several studies have correlated thermal discomfort with low productivity in school and office working environments [2]-[4]. In addition, according to Wyon and Wargocki [5], thermal discomfort also causes distraction, generates complaints and increases the intensity of Sick Building Syndrome (SBS) symptoms. SBS symptoms include headache, nose irritation (stuffy, running), irritated throat, fatigue, dry eyes, difficulty in concentrating, a lack of alertness etc. The literature shows that increased room air temperature resulted in increasing the intensity of symptoms of fatigue, headache and difficulty in concentrating [6], [7]. A field study conducted in an office building, showed that lower temperature, even within the comfort range, reduced the intensity of SBS symptoms [8]. 
Due to fluctuations in solar heat gains, occupancy level and equipment, steady-state conditions are rarely observed in practice. Nevertheless, the majority of human subject experiments examining thermal comfort have been conducted under steady-state conditions and in a thermally uniform environment [7], [9]-[16] or in a non-uniform but constant thermal environment [8], [17]-[22]. Only a few studies have been conducted under transient uniform conditions. Kolarik et al. examined different temperature ramps and observed a linear relationship between mean thermal sensation and operative temperature [7]. In another study examining thermal sensation under transient conditions for sedentary unclothed men, it was found that when the temperature was increasing, the rate of rise of skin temperature caused a sensation that reduced the discomfort caused by the lower skin temperature [15]. Griffiths and McIntyre examined steady state and 3 levels of temperature ramps, both increasing and decreasing, and developed a method for estimating the degree of dissatisfaction produced by temperature changes [23]. Goto et al. investigated the impact of different activity intensity and duration on thermal sensation and concluded that participants' thermal sensation was more sensitive to changes in core temperature caused by a reduction in activity than by increased activity [24]. McIntyre and Gonzalez examined the impact of clothing insulation and activity level on men's thermal sensitivity during rapid temperature drops and found that for resting subjects, thermal sensitivity was not affected by clothing insulation or season [25]. A literature review study of thermal comfort in transient conditions showed that ramps between $0.5 \mathrm{~K} / \mathrm{h}$ and $1.5 \mathrm{~K} / \mathrm{h}$ have no impact on the range of the comfort zone [26]. In all of these studies, either the participants had been acclimatized for a period of time in an environment similar to that of the experiment, to negate any effect of previous activities, or no information was provided about their previous metabolic rate. No study was found that correlated thermal sensation in an office environment with previous activity, e.g. commuting on foot or bicycling. Adaptive thermal comfort has attracted the attention of the thermal comfort community and has been implemented in ASHRAE and CEN standards [27], [28]. The principle of the adaptive approach is that occupants have the possibility to adjust their clothing level, open or close the windows, draw the curtains to reduce solar heat gains, etc. Moujalled et al. conducted a field study in four office buildings in southeast France during Summer-Autumn and found that the subjects' vote was in close agreement with the adaptive control for naturally ventilated buildings [29]. In another study, a survey was conducted in nine schools in Australia during summer and it was found that the more thermally sensitive group of students originated from naturally ventilated schools than air-conditioned schools [30]. Damiati et al. conducted a field study in 13 office buildings in Malaysia, Indonesia, Singapore and Japan running in three different modes (heating, cooling and free-running mode) and found that the results for the free-running mode very mostly within the comfort range of EN 15251 [27]. They also observed that the most frequent personal adaptive behaviour varied among the four countries, namely, turning on the air-condition in Malaysia, or drinking cold beverages in 
Indonesia and Japan [31]. Liu et el. introduced a method to quantify the physiological, behavioural and psychological portions of the adaptation process and concluded that the physiological adaptation was the dominant factor in the creation of an acceptable thermal environment [32]. It should be stated though, that the adaptive approach incorporated in standards is used for the evaluation of buildings where no mechanical system is in use for the condition of the indoor temperature, and the occupants have the freedom to open or close the windows and adjust their clothing level.

Most offices need cooling even in temperate climates like Denmark due to more airtight building envelopes. Several papers and studies show the benefits of using night cooling combined with the active use of thermal mass in the building [33]-[37]. These benefits are mainly due to transferring some of the cooling from day-time to night-time and reduction of the peak load. During night-time the potential for using free cooling (evaporative cooling, increased ventilation with cooler outside temperatures) and the use of lower electricity rates, will result in significant energy benefits. During the day the temperature drifts upwards due to solar heat gains and the internal loads from occupants and equipment. It is however important that the temperature drift within the comfort zone [27], [28]. The study by Kolarik et.al showed that a drift even up to $4.8 \mathrm{~K} / \mathrm{h}$ was acceptable as long as the room temperature stayed in the comfort range [7].

In the existing standards [27], [28], there is a seasonal effect on both the adaptive model and the PMV-PPD approach mainly due to change in clothing level from winter to summer. The effect of a change in metabolic rate (activity level) during the day on the acceptable room temperature has not been studied in detail. Most people will have an increased activity (higher than sedentary) coming to work. This may result in a feeling of warmth arriving in an office controlled for sedentary comfort. A little lower temperature than the comfort range may improve the comfort when arriving in the office and at the same time increase the potential use of night-cooling. The present study investigated that issue, focusing on the conditions in office buildings that can exploit the possibility of night-cooling.

The aim of this study was to examine the impact of increased metabolic rate on thermal sensation when entering an office room that has a lower temperature than is recommended by European Standard 15251 [27]. The authors conducted a human subject experiment in which the effect of commuting to work on foot (estimated and planned to be 2 met on average) was taken into consideration when the participants were asked to evaluate thermal sensation, acceptability and comfort when entering a climate chamber simulating an office space.

\section{Experimental methods}

The experiment was carried out in the climatic chambers of the International Centre for Indoor Environment and Energy (ICIEE) at the Technical University of Denmark (DTU) in the period mid of April to beginning of May. Based 
on the Köppen-Geiger climate classification, Copenhagen is classified as category $\mathrm{Cfb}$, namely, temperate oceanic climate, fully humid with a warm summer. Chamber 3 was constructed to accurately control the thermal environment [38]. Its dimensions are $5 \mathrm{~m} \times 6 \mathrm{~m} \times 2.5 \mathrm{~m}$ and the walls are made of two layers of porous vinyl sheets. Air was supplied to the chamber through the floor (equally distributed), and by penetrating the vinyl wall-sheets. This construction ensured identical room air and mean radiant temperature, and consequently an operative temperature equal to air temperature. Prior to the experiment, the authors took air speed measurements in several locations inside the room, using heat dummies in the positions to be occupied by the subjects, to simulate the conditions and the heat gains of the actual experiment. This pre-test study of the distributed physical room conditions was conducted to ensure that the office-lab had the standardized acceptable room conditions without causing any draft, thermal discomfort or air movement discomfort. The anemometers were installed on a vertical stand at $0.1 \mathrm{~m}, 0.3 \mathrm{~m}, 0.6 \mathrm{~m}, 0.9 \mathrm{~m}, 1.1 \mathrm{~m}, 1.4 \mathrm{~m}$, $1.7 \mathrm{~m}$, and $2 \mathrm{~m}$ above the floor to examine the vertical stratification. The highest air speed measured was $0.09 \mathrm{~m} / \mathrm{s}$, which was considered unlikely to affect the thermal comfort of the participants. Figure 1 shows the results of the air speed measurements, while the location of the points of measurement are shown in Figure 2.

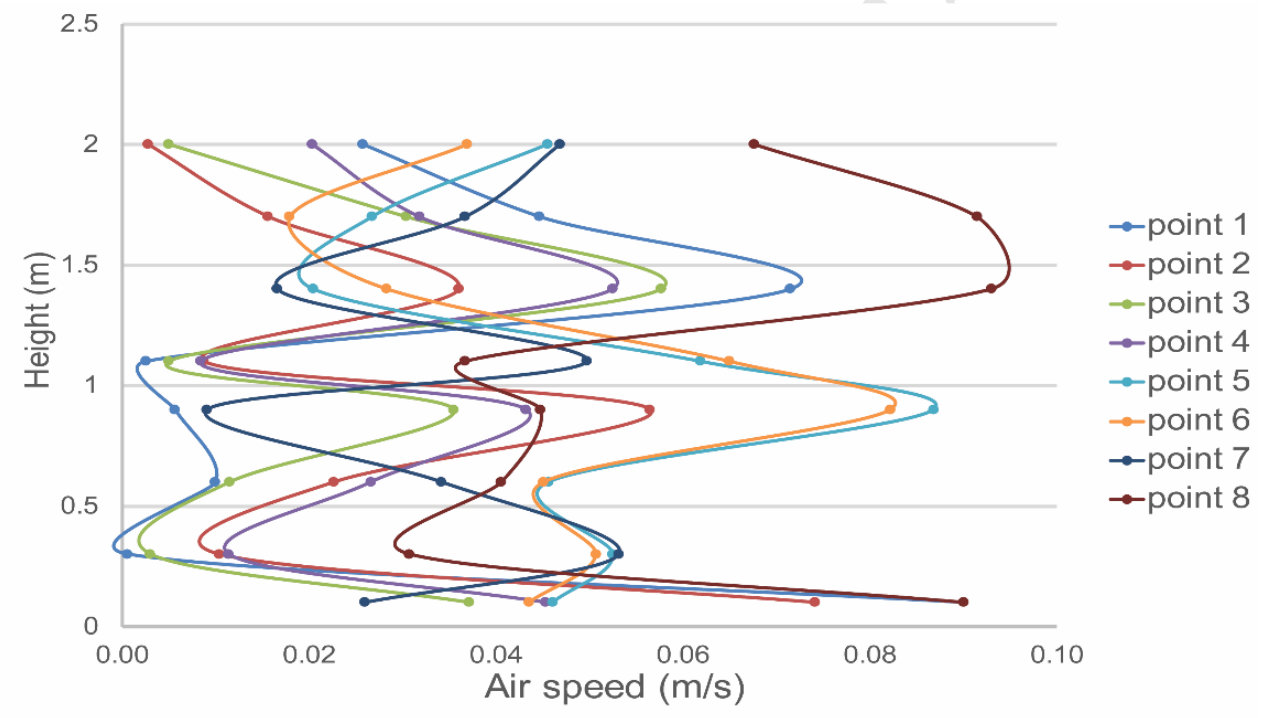

Figure 1: Air speed measurements at different heights and locations in Chamber 3

Initially, 30 DTU students were recruited and allocated randomly to groups of five. Their age varied from 22 to 27 years old, they were healthy and physically fit and they all had a normal Body Mass Index (BMI), namely between 18.5 and $25 \mathrm{~kg} / \mathrm{m}^{2}$. BMI is obtained by dividing a person's weight (in $\mathrm{kg}$ ) by the square of his/her height (in metres). The participants were requested to wear light summer clothing and this resulted in an effective clo-value of 0.5 when the insulation of an office chair was included (ASHRAE Standard 55 Table 5.2.2.2C [28]). Each subject participated in four 
different sessions, experiencing each session only once. Two sessions were executed per day, one starting at 8:30 and one starting 13:00. To minimize possible bias caused by the order of exposure, the four sessions were spread randomly during the three weeks of the experiment, and it was ensured that no participant would come twice on the same day or on consecutive days. By the end of the experiment, only 25 subjects had participated in all four sessions, so only their responses were processed. Due to absence, the number of participants in each session varied from three to five, as is common in an open-office work situation. Table 1 shows the anthropometric information for the 25 remaining participants.

Table 1: Anthropometric data of the experiment participants

\begin{tabular}{lllll}
\hline Genre & Age & Height, & Weight, & BMI, \\
& & $\mathrm{cm}$ & $\mathrm{kg}$ & $\mathrm{kg} / \mathrm{m}^{2}$ \\
\hline Female & $25 \pm 1.4$ & $1.67 \pm 0.07$ & $61.2 \pm 6.7$ & $21.9 \pm 2.4$ \\
Male & $25 \pm 1.6$ & $1.81 \pm 0.07$ & $75.9 \pm 5.8$ & $23.2 \pm 0.8$ \\
& & & & \\
Both & $25 \pm 1.5$ & $1.74 \pm 0.1$ & $68.5 \pm 9.7$ & $22.5 \pm 1.8$ \\
& & & & \\
\hline
\end{tabular}

Each session consisted of two phases: the commute phase, which simulated commuting to work on foot, and the office phase. This climatic chamber was furnished to represent a five-person landscape office: each participant was provided with a desk, a chair, and a laptop connected to the internet. Upon arrival, all participants were fitted with a heart rate sensor. In addition, four iButton skin temperature sensors (accuracy $\pm 0.5^{\circ} \mathrm{C}$ ) were placed on each participant, on the forehead, the right palm, the right scapula and the right shin, so that local skin temperature and an estimate of the areaweighted mean skin temperature could be recorded. The level of skin temperature can cause both local and whole body thermal discomfort. Therefore, the authors recorded the participants' skin temperature to examine whether any extremely low or high skin temperature values were recorded. Heart rate and skin temperature were measured throughout each session.

The first part of the experiment was conducted in a HVAC controlled office room with a view of the garden outside. In this room the average outdoor air temperature for Northern European summer weather conditions at the typical working day commuting time, from 07:00 to 09:00, was maintained $\left(18^{\circ} \mathrm{C}\right)$. For this commute session, three treadmills and two steps were installed on which the subjects exercised for 15 minutes at an average activity level of 1.5 met. In order for 
all participants to have equivalent activity levels, the subjects switched positions so that they exercised for a total of 9 minutes on the treadmill and 6 minutes on the steps.

After the commuting session, the participants walked directly into the conditioned office room and sat down at their assigned desk (second experimental session). Figure 2 shows a graphical representation of the conditioned office room, the location of the five desks and the locations where the air speed measurements shown in Figure 1 were taken. The star in the centre of figure shows the location of the stand with the air and operative sensors controlling the conditions in the chamber. The distance between the subjects was one meter, to ensure that any effect of convective or radiative heat exchange with adjacent subjects was negligible.

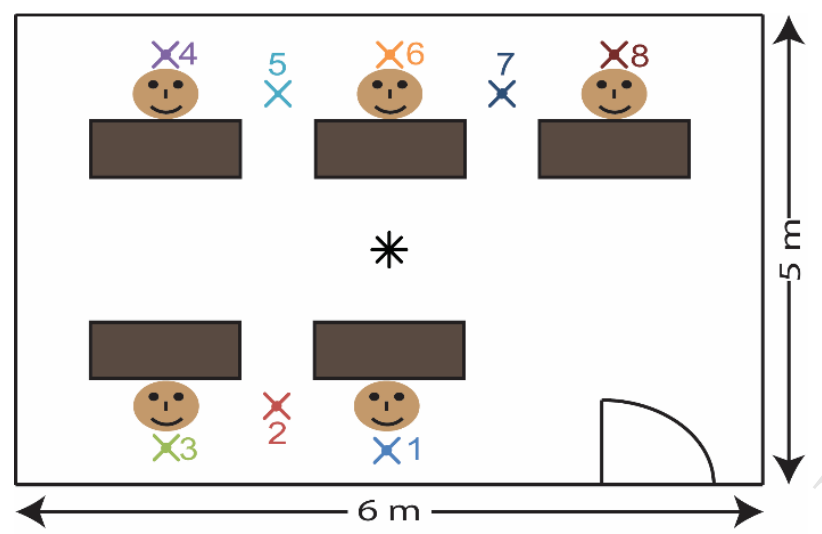

Figure 2: Graphical representation of the conditioned office room, the location of the five desks, the air speed measurements and the stand with the control air and operative temperature sensors

At the beginning and end of each session and at 30-minute intervals throughout the session, the participants were requested to complete an online questionnaire. In the meantime, participants played various simple games on the computer (e.g. Sudoku) to replicate a normal office activity level. In the questionnaires, the participants reported thermal sensation, thermal comfort, the acceptability of the thermal conditions at that specific moment and the intensity of any SBS symptoms. The SBS symptoms included in the questionnaires were headache, nose irritation (stuffy, running), irritated throat, fatigue, dry eyes, difficulty in concentrating and sleepiness. When conducting a human subject experiment, the questionnaire should include more questions than those necessary for the particular study, to have a complete knowledge of the indoor environment quality (IEQ) parameters of the built offices' environment and to ensure that the participants will work blind of the aim the investigation to avoid bias. In the present case, the authors had included questions about air quality, noise level, lighting intensity etc. Figure 3 shows some of the questions included in the questionnaires. 


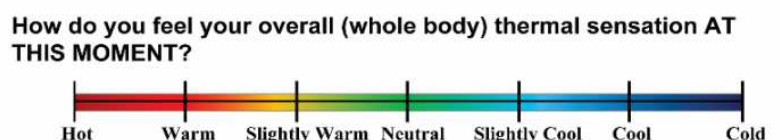

And, How acceptable is it (your whole body thermal sensation) AT THIS MOMENT for you?

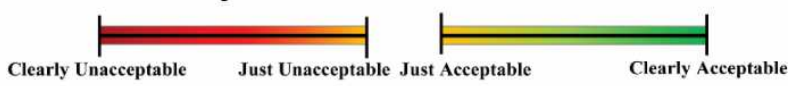

How do you FEEL your overall thermal sensation at this precise moment?

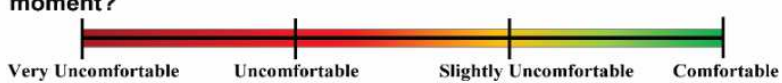

How do you rate the air quality?

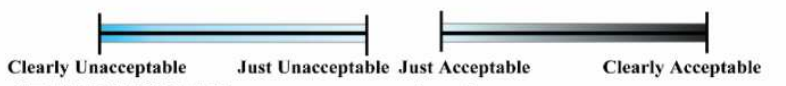

AT THIS MOMENT, are you experiencing:

Headache

vES

Nose irritation (stuffy, running)

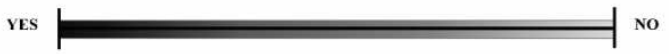

Figure 3: Some of the questions included in the questionnaires

During this phase of the experiment, the air temperature was increased by $1.5^{\circ} \mathrm{C}$ every 30 minutes, and then kept constant during the last 30 minutes. According to ASHRAE Standard 55 [28], the room temperature increase within 30 minutes should be no more than $1.7 \mathrm{~K}$, so the temperature ramp complied with the suggested limits. The relative humidity was kept constant around $50 \%$. Table 2 shows the temperature schedule for the four different sessions examined, whose duration varied.

Table 2: Temperature schedule for the 4 sessions

\begin{tabular}{llllllll}
\hline Time of & $00: 00$ & $00: 30$ & $01: 00$ & $01: 30$ & $02: 00$ & $02: 30$ & $03: 00$ \\
change & & & & & & & \\
\hline Case 1 & $18.5^{\circ} \mathrm{C}$ & $20^{\circ} \mathrm{C}$ & $21.5^{\circ} \mathrm{C}$ & $23^{\circ} \mathrm{C}$ & $24.5^{\circ} \mathrm{C}$ & $24.5^{\circ} \mathrm{C}$ & \\
Case 2 & $20^{\circ} \mathrm{C}$ & $21.5^{\circ} \mathrm{C}$ & $23^{\circ} \mathrm{C}$ & $24.5^{\circ} \mathrm{C}$ & $26^{\circ} \mathrm{C}$ & $27.5^{\circ} \mathrm{C}$ & $27.5^{\circ} \mathrm{C}$ \\
Case 3 & $21.5^{\circ} \mathrm{C}$ & $23^{\circ} \mathrm{C}$ & $24.5^{\circ} \mathrm{C}$ & $26^{\circ} \mathrm{C}$ & $26^{\circ} \mathrm{C}$ & & \\
Case 4 & $23^{\circ} \mathrm{C}$ & $24.5^{\circ} \mathrm{C}$ & $26^{\circ} \mathrm{C}$ & $27.5^{\circ} \mathrm{C}$ & $27.5^{\circ} \mathrm{C}$ & & \\
\hline
\end{tabular}

\section{Results}

\subsection{Gender comparison}

Random- and mixed-effects models were used to examine the significance of differences between temperatures for all three thermal comfort questions (sensation, acceptability and comfort). Quantile-quantile plots (QQ-plots) were used to test whether the residuals were normally distributed. The P-level for significance was set to 0.05 as in a similar study 
[7]. Table 3 shows the p-values for the responses of thermal sensation, thermal acceptability and thermal comfort between the male and female participants. No significant gender difference was found, so in the rest of the thermal comfort analysis their responses were pooled. When combining the two gender results (as no significant difference was observed), the results were very close to being normally distributed. Therefore, it was decided to use mean values and standard deviation to describe them.

Table 3: p-values for a gender difference in responses to the thermal comfort questions

\begin{tabular}{cccc}
\hline & $\begin{array}{c}\text { Whole body } \\
\text { thermal sensation }\end{array}$ & $\begin{array}{c}\text { Thermal sensation } \\
\text { acceptability }\end{array}$ & Thermal \\
& 0.78 & 0.74 & 0.87 \\
Case 1 & 0.70 & 0.57 & 0.91 \\
Case 2 & 0.66 & 0.71 & 0.70 \\
Case 3 & 0.58 & 0.33 & 0.28 \\
Case 4 & & & \\
\end{tabular}

\subsection{Skin temperature}

As for the responses to the thermal comfort questions, it was first determined whether there was a significant difference between the responses of male and female participants. Table 4 shows the p-values for the skin temperature measurements. No significant differences were observed for the sensors placed on the right hand and the forehead of the participants, namely the two sensors that were exposed directly to room air. On the other hand, for the two sensors that were covered by the participants' clothing, significant differences were observed between the responses of the two genders. The cells highlighted in bold were the cases in which a significant difference was found. Female participants had higher skin temperature on the right scapula during the whole session, while male participants had higher skin temperature on their right shin throughout the whole session.

Table 4: $p$ values for a gender difference in skin temperatures

\begin{tabular}{ccccc}
\hline & $\begin{array}{c}\text { Right } \\
\text { hand }\end{array}$ & Forehead & Right & Right \\
& & & scapula & shin \\
\hline Case 1 & 0.51 & 0.53 & $\mathbf{0 . 0 1}$ & 0.41 \\
Case 2 & 0.52 & 0.47 & $\mathbf{0 . 0 2}$ & 0.15 \\
Case 3 & 0.38 & 0.36 & 0.14 & $\mathbf{0 . 0 3}$
\end{tabular}




$\begin{array}{lllll}\text { Case } 4 & 0.48 & 0.83 & 0.98 & \mathbf{0 . 0 1}\end{array}$

Figure 4 shows the average skin temperature of all participants on the forehead, the right palm, the right scapula and the right shin, for each case separately. The vertical black dashed line separates the figures into the exercise phase on the left side of the line and the office phase on the right side of the line. At the end of the exercise period, all four cases had almost the same skin temperature in all four locations measured, since the PV Lab maintained a constant temperature throughout the experiment. The temperature differences measured in the four cases on the scapula and the shin were not significant, since these two sensors were covered by the participants' clothing. A similar trend was also observed on the forehead, although this sensor was exposed and in direct contact with room air. On the other hand, the temperature differences measured on the palm sensor differed markedly between cases. At thermal neutrality, skin temperature is around $33^{\circ} \mathrm{C}$ and the flow of energy to and from the skin determines a person's sense of hot and cold. No extreme values were recorded, that could have caused local or whole-body thermal discomfort. 

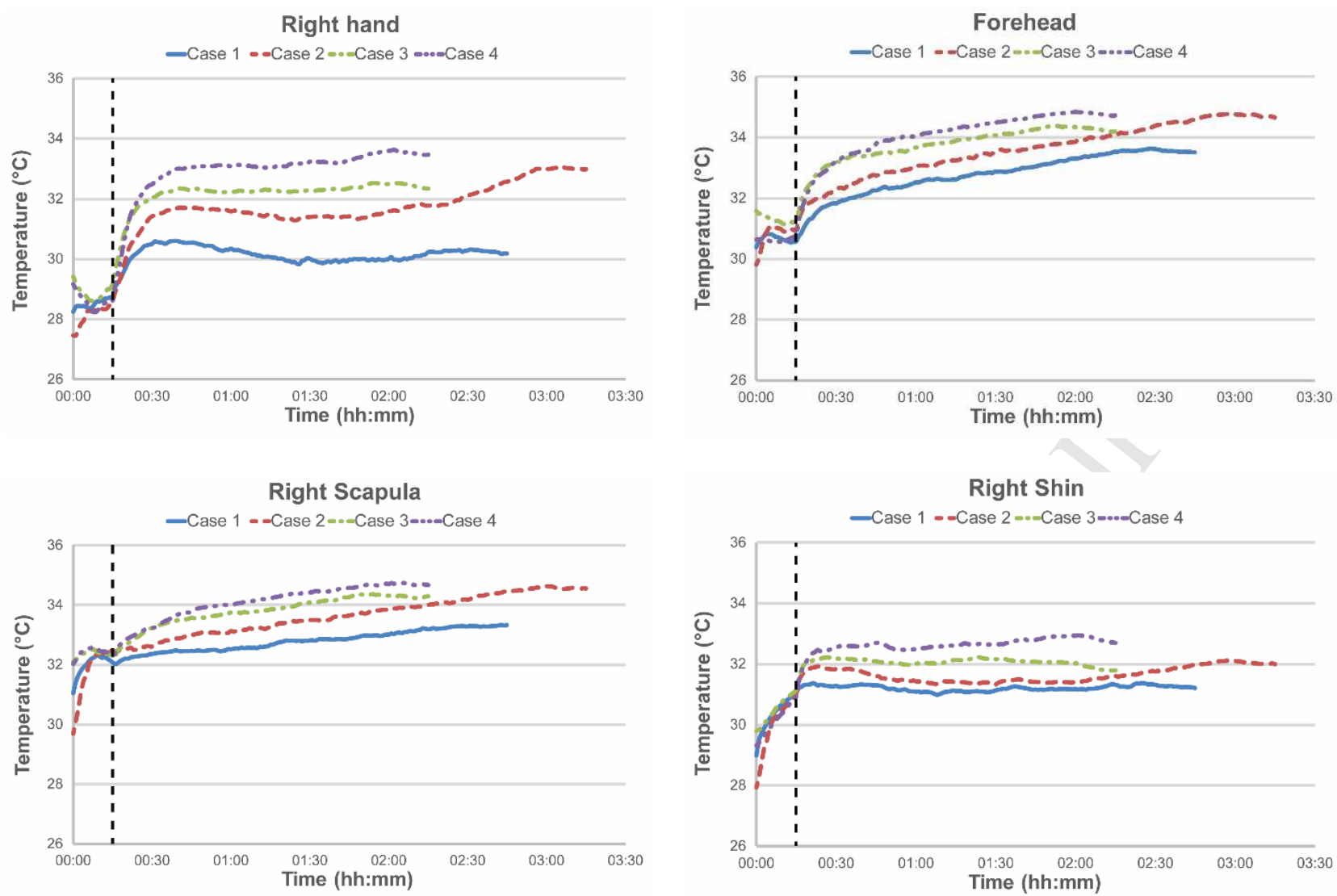

Figure 4: Average skin temperature for each case

\subsection{Whole body thermal sensation}

Figure 5 shows the whole body thermal sensation and its standard deviation as a function of the room temperature. At the starting temperature of $18.5^{\circ} \mathrm{C}$, the subjects felt closest to neutral when they entered the chamber, compared to the other three cases. The effect of exercising quickly decreased, and subjects reported feeling slightly cool in the second questionnaire of Case 1. This indicates that after half an hour, the results are largely dependent on the room temperature, and unaffected by any preceding activity. The responses were close to neutral again only when the room temperature was at least $23^{\circ} \mathrm{C}$. This corresponds to what was proposed by European Standard 15251 [27]. A temperature range of $23-24.5^{\circ} \mathrm{C}$ was proposed as the most neutral. When the participants entered the chamber at the room temperatures of $21.5^{\circ} \mathrm{C}$ and $23^{\circ} \mathrm{C}$ (Cases 3 and 4 respectively), they reported slightly warm thermal sensations. Figure 5 confirms that $24.5^{\circ} \mathrm{C}$ was the most neutral temperature. When the temperature remained constant at $27.5^{\circ} \mathrm{C}$ (the last 30 minutes of Cases 2 and 4), the subjects adapted to it even though it is above the upper limit of Category III of the Standard 15251 , namely $27^{\circ} \mathrm{C}$ [27]. Furthermore, although the starting temperature of Cases 2 and 4 differed by 3 $\mathrm{K}$, after $26^{\circ} \mathrm{C}$ the participants' responses were almost identical. The starting point of each session thus had no influence at the end of each session. By calculating the area under each curve, it was found that the case that deviated the least from the neutral point was Case 3. This was due to the fact that after the initial 30 minutes, the room temperature was 


\section{ACCEPTED MANUSCRIPT}

$23 \mathrm{~K}$ and therefore remained for most of the time period within the neutral range of Category II of Standard 15251, namely $23^{\circ} \mathrm{C}-26^{\circ} \mathrm{C}[27]$.

Kolarik et al. [7] reported whole body thermal sensation of approximately -0.5 when the starting room air temperature was $22^{\circ} \mathrm{C}$, the clo-value 0.5 and the metabolic rate 1.2 met. In the present study, the closest starting room air temperature was $21.5^{\circ} \mathrm{C}$ (Case 3 ) for which the mean whole-body thermal sensation was 1.06 . Although in the present study the room air temperature was $0.5 \mathrm{~K}$ lower, whole-body thermal sensation was significantly higher when entering the chamber. This difference is attributed to the different metabolic rate values in the two experiments.

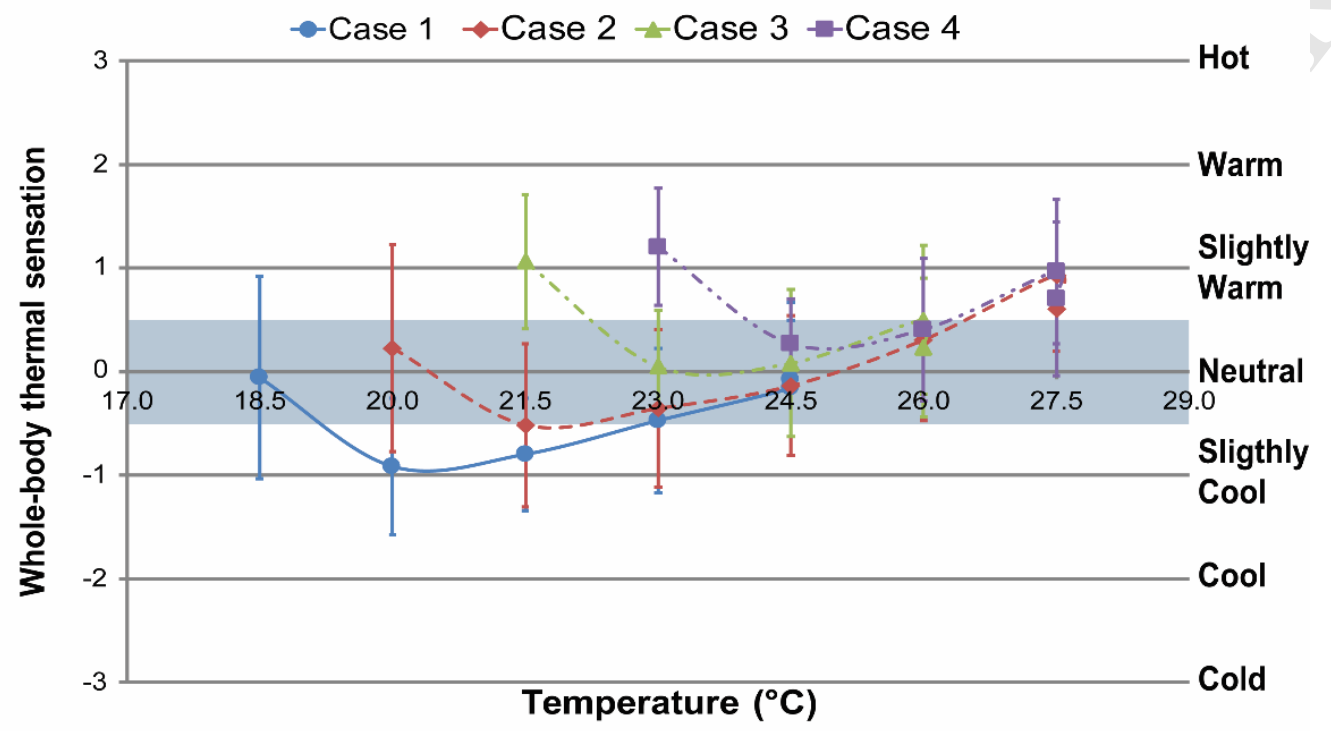

Figure 5: Whole-body thermal sensation as a function of the room air temperature. Whiskers show the standard deviation for each questionnaire

Figure 6 shows the whole-body thermal sensation in boxplots, separately for male and female participants, for the first questionnaire. In all four cases, the responses from each gender were quite similar. In Cases 1 and 2 the median and the $\pm 25 \%$ of the responses were around neutral, while in Cases 3 and 4 they reached a slightly warm value. In Cases 3 and 4 the box indicating the central $50 \%$ of responses is smaller, which indicates less variation between the responses of different subjects. This figure also supports the previous conclusion that the differences between male and female subjects were small. 
Case 1

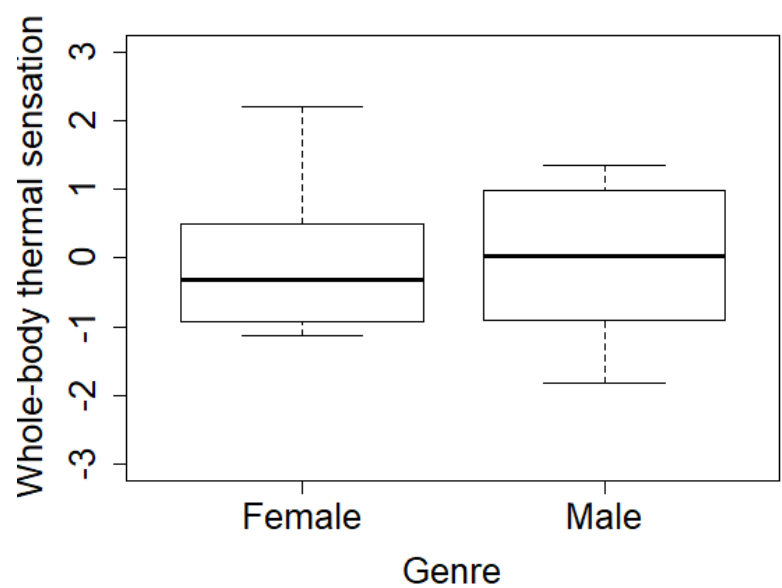

Case 3

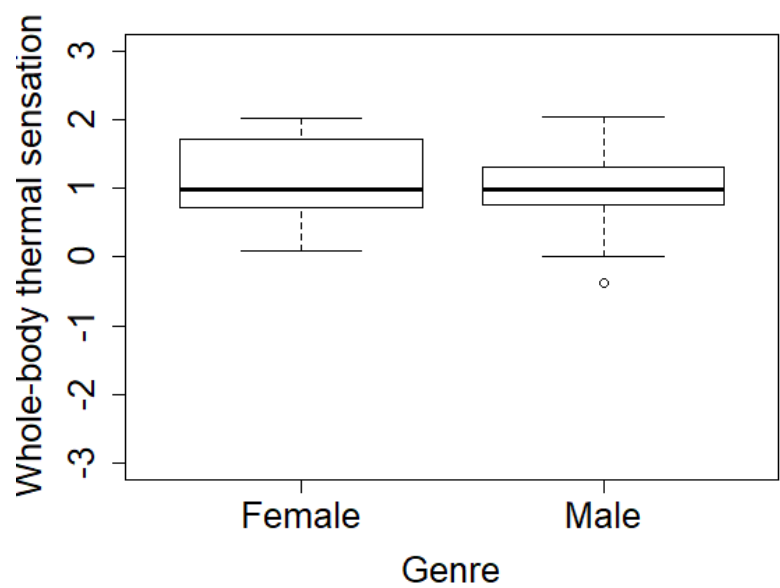

Case 2

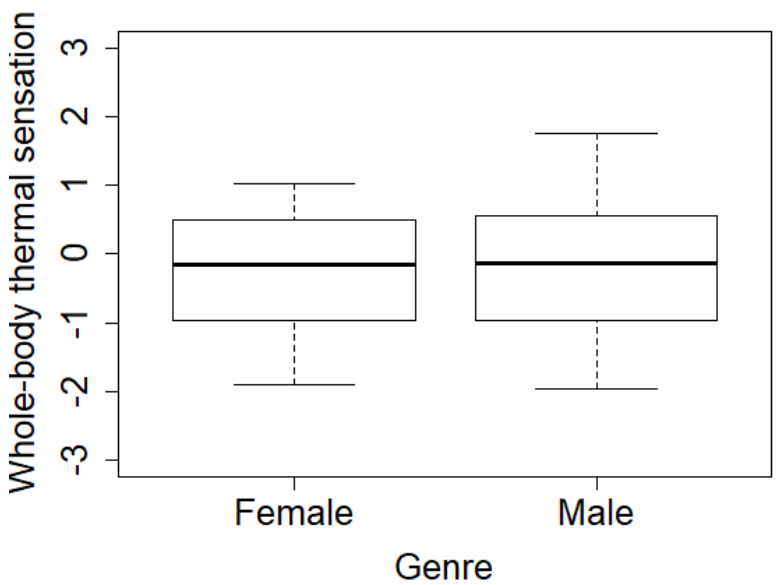

Case 4

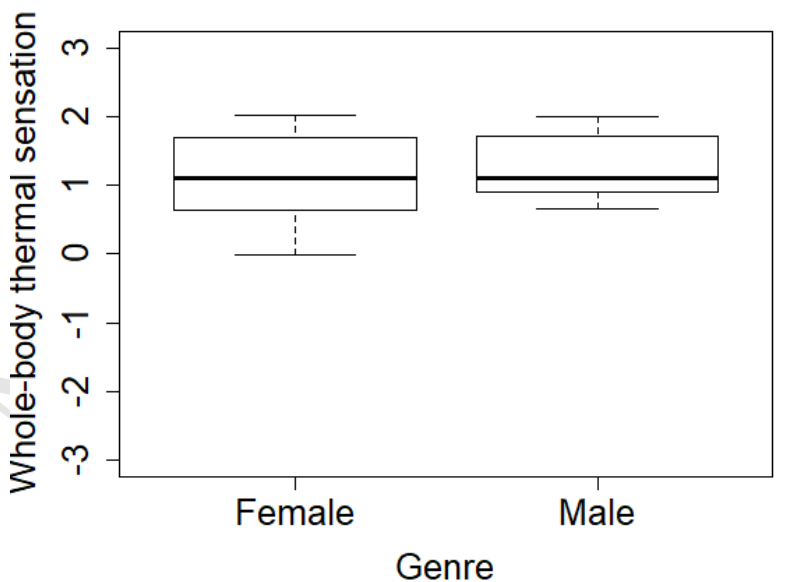

Figure 6: Whole-body thermal sensation for the first questionnaire of each case separately

\subsection{Whole-body thermal acceptability}

Figure 7 shows the mean values of the whole-body thermal acceptability as a function of the room temperature. As before, the lower the room temperature at the beginning of the session, the higher the acceptability. Case 1 was the only case that returned a lower acceptability value at the second questionnaire compared to the first one, meaning that once the participants' metabolic rate dropped to a value typical of office work, a room air temperature of $20^{\circ} \mathrm{C}$ proved to be too low. On the other hand, Case 2 , with a starting temperature of $20^{\circ} \mathrm{C}$ followed by the $1.5 \mathrm{~K} / 0.5 \mathrm{~h} \mathrm{ramp}$, had the highest acceptability value before it exceeded $26^{\circ} \mathrm{C}$, which is the upper limit of Category II of Standard 15251 [27]. Case 2 yielded the highest acceptability: from $21^{\circ} \mathrm{C}$ to $26^{\circ} \mathrm{C}$ the thermal acceptability remained almost unchanged. The lowest acceptability was recorded in the initial questionnaire of Case 4 , when the room temperature was $23^{\circ} \mathrm{C}$. 


\section{ACCEPTED MANUSCRIPT}

Although this is the lower limit of Category II of Standard 15251, it was considered as just acceptable. Due to the decrease in the subjects' metabolic rate, the increased room temperature at the second questionnaire was reported as more acceptable. A similar trend was also observed in Case 3, but with slightly higher values of thermal acceptability.

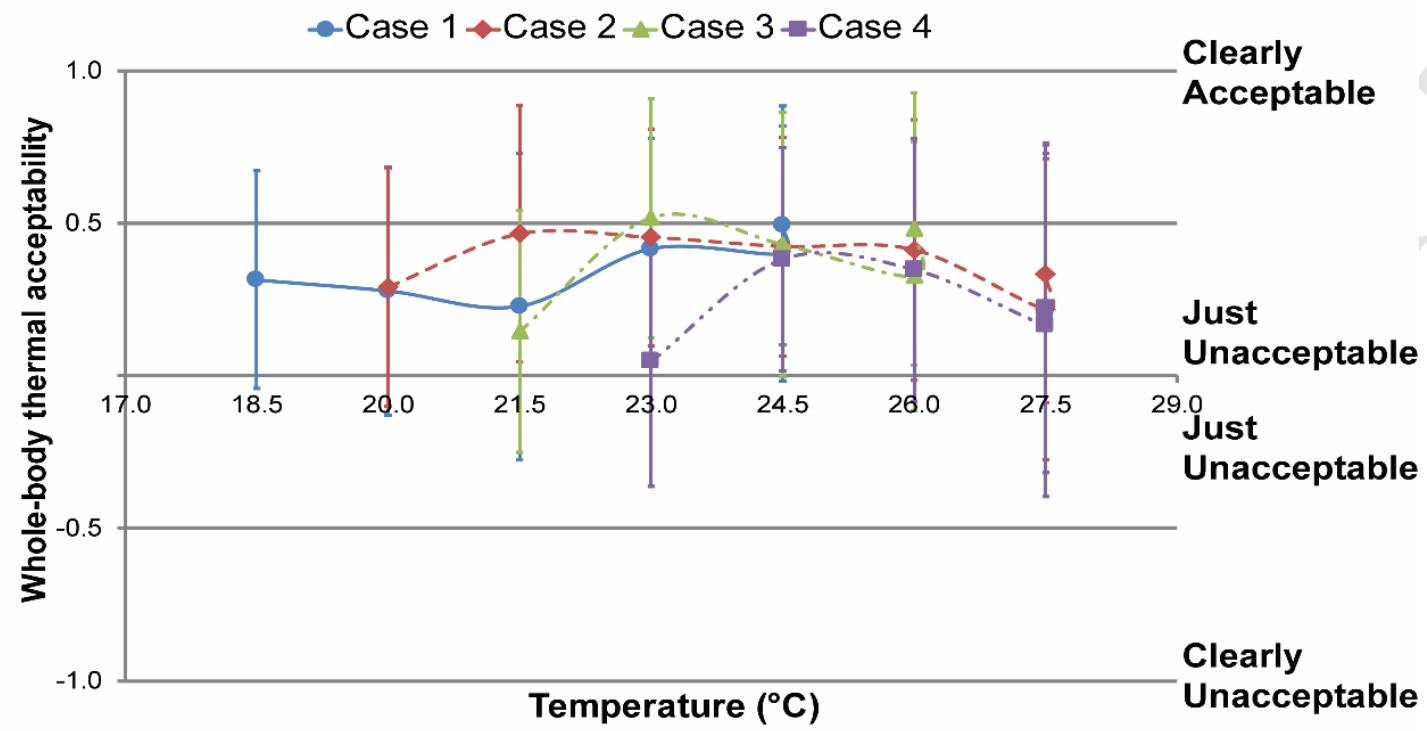

Figure 7: Whole-body thermal acceptability as a function of the room temperature. Whiskers show the standard deviation for each questionnaire

\subsection{Whole body thermal comfort}

Figure 8 shows whole-body thermal comfort as a function of room temperature. As before, the lower starting room temperature of the first two experimental cases yielded the highest values of thermal comfort at the beginning of each session, although this time the differences were smaller. For all the experimental cases, whole-body thermal comfort was always above the "slightly uncomfortable" level. When the room temperature exceeded $26^{\circ} \mathrm{C}(\mathrm{Cases} 2$ and 4$)$, the room temperature was evaluated as less comfortable. In all four cases, when the room temperature remained constant at the end of the sessions, participants felt slightly more comfortable after being exposed to the same temperature for 30 minutes. The most comfortable temperature range was $23^{\circ} \mathrm{C}-26^{\circ} \mathrm{C}$. Case 1 was the only case in which the participants felt less comfortable at the second questionnaire than at the first questionnaire. Overall, Case 2 was considered the most comfortable. 


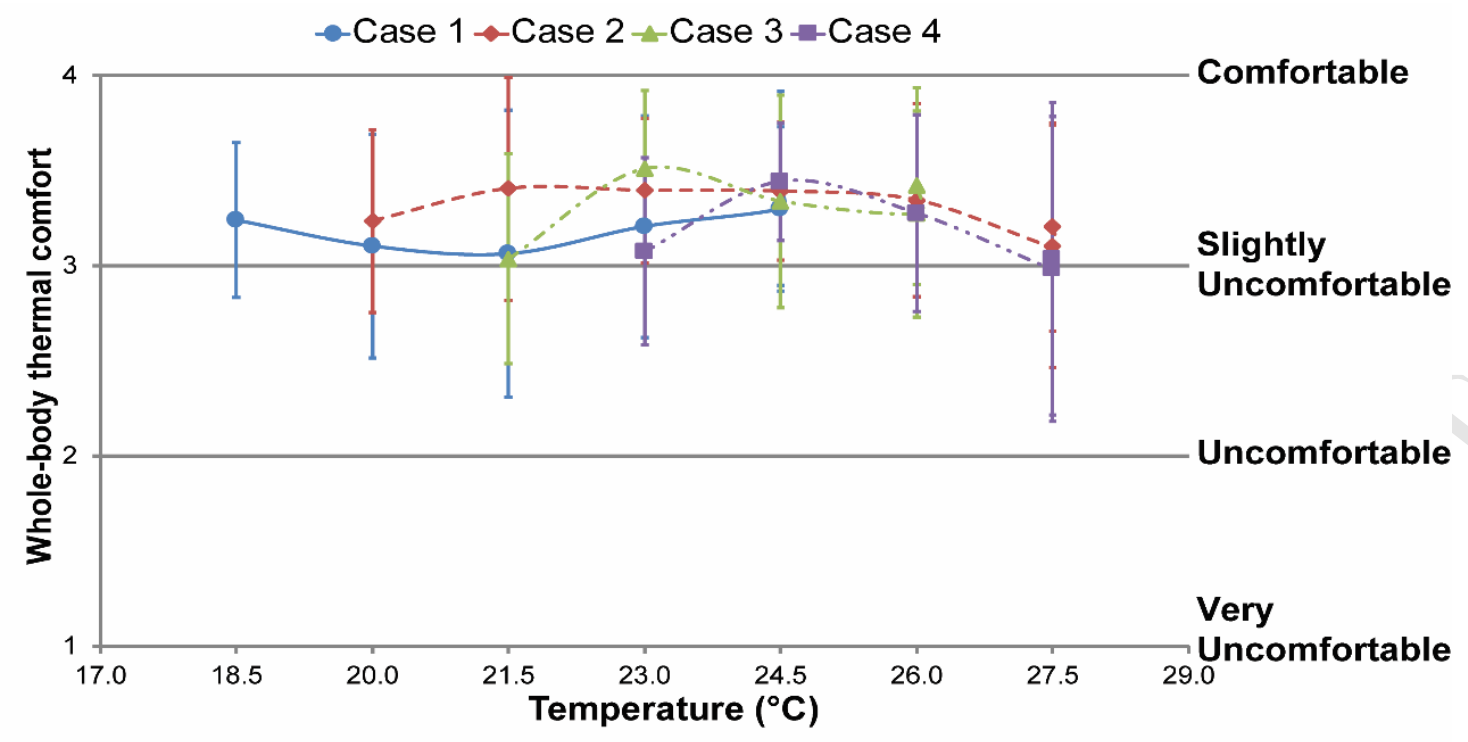

Figure 8: Whole-body thermal comfort as a function of the room temperature. Whiskers show the standard deviation for each questionnaire

\subsection{Percentage dissatisfied}

Figure 9 shows the percentage of the subjects dissatisfied with the thermal environment as a function of the mean thermal sensation, for each case separately. The predicted percentage dissatisfied (PPD) curve derived from Fanger's model is also included in these figures for comparison [39]. For every questionnaire, the thermal sensation was the average value of the thermal sensation responses of all the participants. Cases 1, 2 and 4 follow Fanger's curve quite closely, while Case 3 does not. Figure 10 shows all the results combined in order to plot the trendline more accurately. Although the conditions in this experiment were transient (temperature ramp of $1.5 \mathrm{~K} / 0.5 \mathrm{~h}$ ), the results in the neutral zone follow Fanger's model quite closely, although it was developed from data obtained in steady-state studies. Kolarik et al. [7] made a similar observation in their study. These are strong indications that Fanger's model has a broader range of application and this should be further investigated to well outside the limits of a steady-state condition. 


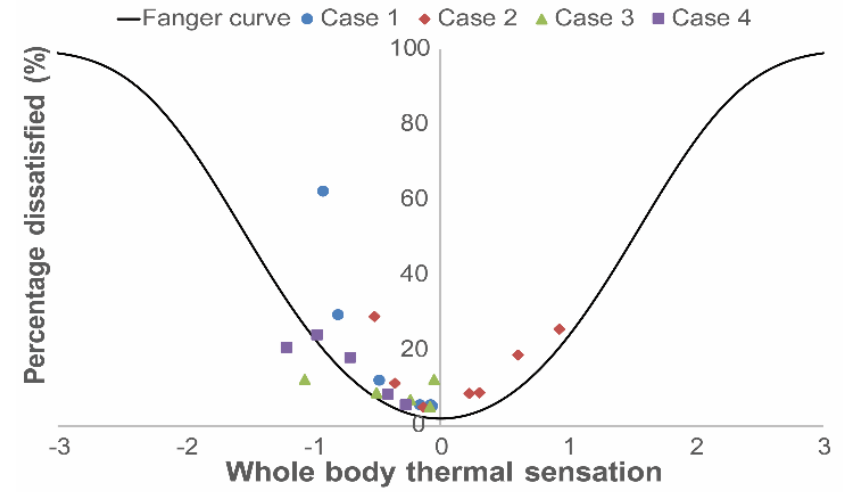

Figure 9: Percentage of subjects dissatisfied with the thermal environment, for each case separately

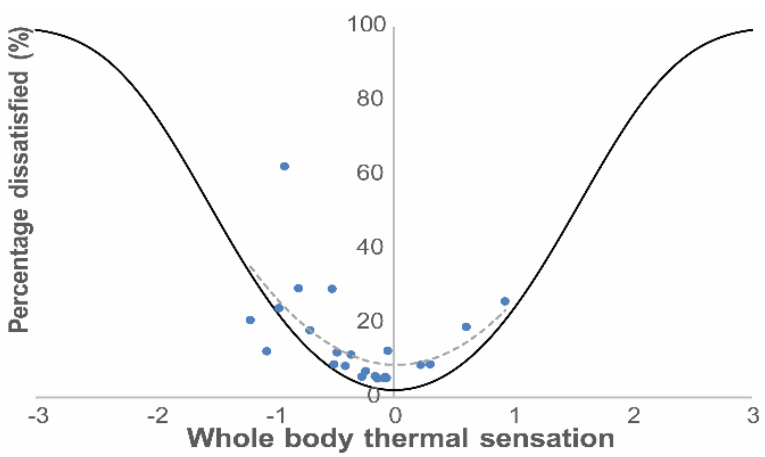

Figure 10: Combined results of percentage of subjects dissatisfied with the thermal environment

\subsection{Sick building syndrome (SBS) symptoms}

Table 5 summarizes the results of the subjects' responses to questions about their sick building syndrome symptoms. An arrow pointing downwards means that there was a significant deterioration in that symptom as room air temperature increased, while NS means that there was no significant change, either positive or negative. In most cases a deterioration was observed in the general symptoms (fatigue, lack of concentration, sleepiness) and less often in the specific symptoms (headache, nose irritation, etc.). The cause of the deterioration of the general symptoms could be the quality of the artificial light in the climatic chamber or the fact that this chamber has no windows.

Table 5: Intensity of SBS Symptoms

\begin{tabular}{|c|c|c|c|c|c|c|c|}
\hline & Headache & $\begin{array}{c}\text { Nose } \\
\text { Irritation }\end{array}$ & $\begin{array}{l}\text { Throat } \\
\text { Irritation }\end{array}$ & $\begin{array}{c}\text { Eyes } \\
\text { Irritation }\end{array}$ & Fatigue & Concentration & Sleepiness \\
\hline Case 1 & NS & NS & $\mathrm{NS}$ & $\mathrm{NS}$ & $\downarrow$ & $\downarrow$ & NS \\
\hline Case 2 & NS & NS & NS & $\downarrow$ & NS & $\downarrow$ & NS \\
\hline Case 3 & $\downarrow$ & NS & NS & NS & $\downarrow$ & $\downarrow$ & NS \\
\hline Case 4 & $\downarrow$ & NS & NS & NS & $\downarrow$ & $\downarrow$ & $\downarrow$ \\
\hline
\end{tabular}

Figure 11 shows examples of the evolution of the intensity of a specific symptom (throat irritation) and a general symptom (difficulty in concentrating). A symptom intensity of 100 means that the subject felt no irritation, while 0 mean severe irritation. For throat irritation, a deterioration was observed in all cases, but the effect was small. For example, in Case 1, the maximum value was 97 (recorded at the first questionnaire), while the lowest was 90 (recorded at the last questionnaire). On the other hand, in every case the ability to concentrate showed the most significant 


\section{ACCEPTED MANUSCRIPT}

deterioration. For example, in Case 1, the maximum value was 92 (first questionnaire), while the lowest value recorded was 74 (penultimate questionnaire). Regardless of the symptom, in most cases an improvement was observed when the temperature was kept constant during the last 30 minutes. A deterioration of the SBS symptoms observed with an increase in room air temperature is consistent with other findings in the literature [6]-[8].

Case 1

- Throat= Concentration

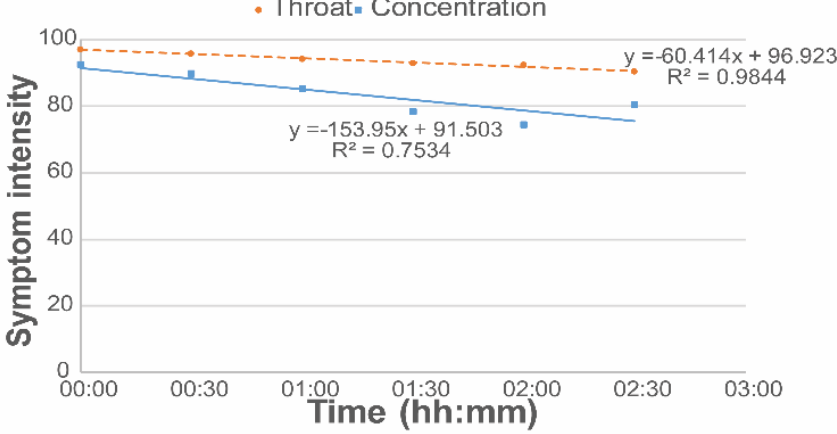

Case 3

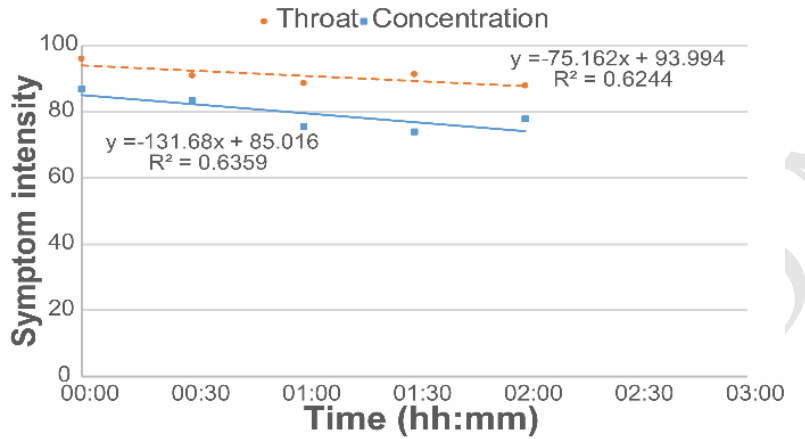

Case 2

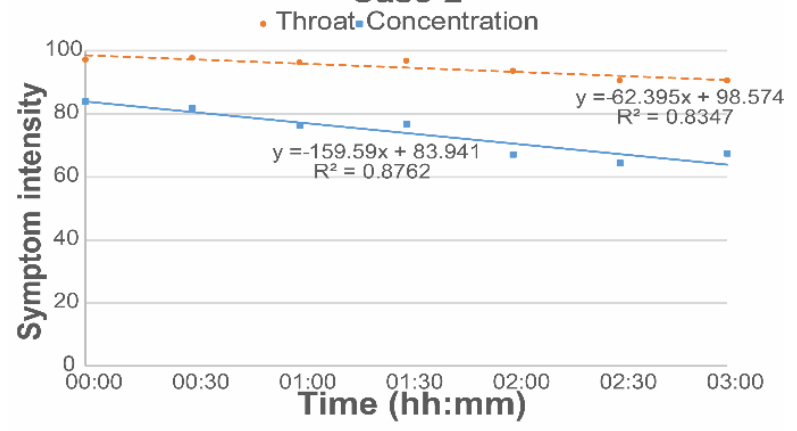

Case 4

- Throat" Concentration

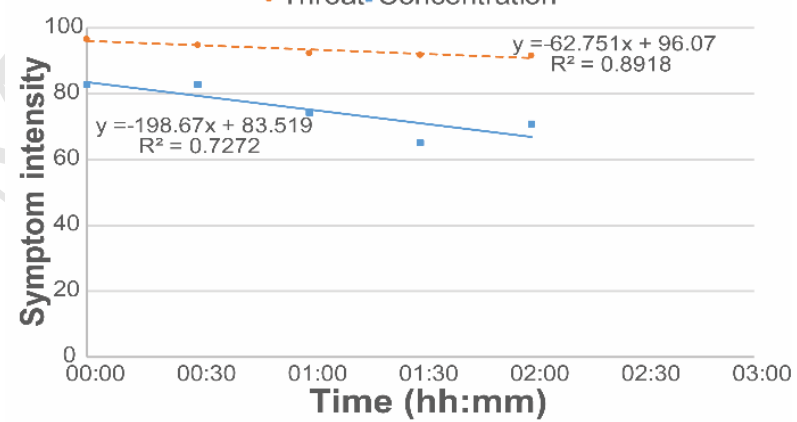

Figure 11: Examples of development of sick building syndrome symptoms for each case examined

\section{Discussion}

The significant differences observed between the four experimental cases in Figure 5 were not reflected in similar differences in Figure 7 or Figure 8. Whole-body thermal sensation varied from slightly cool to slightly warm, thermal acceptability was always better than "just acceptable" while whole-body thermal comfort was always better than "slightly uncomfortable". The course of the curves of thermal acceptability and thermal comfort shown in Figure 7 and Figure 8 are almost identical, although the question that was used to report thermal comfort was a continuous scale while for thermal acceptability it was not, as shown in Figure 3.

There are certain limitations in the present study that should be taken into consideration. These limitations are related to the experimental factors that were restricted to a specific value or range of values, to avoid possible bias. These factors 
include the clo-value of the participants and the anthropometric parameters of the subjects. The clo-value was limited to 0.5 , the subjects' age was in a narrow range (22-27 years old) and only subjects with normal body mass index were accepted. In other words, underweight, overweight or obese people were excluded from this study. The interior of the climate chamber used for the experiment was designed to simulate a landscape office. The dimensions of the climate chamber could not be changed however, so not more than 5 participants at the same time could be present. Nevertheless, the findings of the study would not be affected whether the authors had simulated a landscape or a cellular office room. When selecting the temperature rate of change, the limitation of $1.7 \mathrm{~K} / 0.5 \mathrm{~h}$ had to be taken into consideration, based on ASHRAE Standard 55 [28]. Apart from that restriction, the choice was arbitrary. The ramp of $1.5 \mathrm{~K} / 0.5 \mathrm{~h}$ used in this study is close to the maximum allowed. Increasing the ramp to $1.7 \mathrm{~K} / 0.5 \mathrm{~h}$ most probably would not cause significant differences since $0.2 \mathrm{~K}$ is a very small temperature difference and unlikely to be perceived. Reducing the slope of the ramp to e.g. $1 \mathrm{~K} / 0.5 \mathrm{~h}$ would result in increased thermal discomfort after the first 30 minutes, as Figure 5, Figure 7 and Figure 8 show, because it will take more time to reach the comfort range of $23-26^{\circ} \mathrm{C}$ for sedentary activity. The authors therefore believe that no useful findings would be obtained by examining different ramps in relation to the purpose of the present study. No extensive study of typical office temperatures in Denmark in summer was found and using one-building cases would be too risky due to the high degree of variability (building orientation, construction properties, occupancy level, etc.). Nevertheless, the Danish building code, which is based on ISO 7730 [1], recommends that office buildings should operate in the range of $20-24^{\circ} \mathrm{C}$ during winter and $23-26^{\circ} \mathrm{C}$ during summer. Therefore, most buildings may be assumed to operate in this interval.

After having exercised for 15 minutes the participants preferred a lower room air temperature than is suggested by the standards, so in countries where most people commute on foot or on a bicycle, at the beginning of the occupancy period the office room temperature should be lower than $23^{\circ} \mathrm{C}$. Although $18.5^{\circ} \mathrm{C}$ as a starting temperature had the highest thermal acceptability and comfort value, it must be considered as too low, as it took longer to reach the range of $23^{\circ} \mathrm{C}-$ $26^{\circ} \mathrm{C}$, because the maximum allowed room temperature increase in 30 minutes is $1.7 \mathrm{~K}$ [28]. We therefore suggest that the starting room temperature should be $20^{\circ} \mathrm{C}-21.5^{\circ} \mathrm{C}$ and that room temperature should then increase at the rate of $1.5 \mathrm{~K} / 0.5 \mathrm{~h}$ to reach the comfort range of $23^{\circ} \mathrm{C}-26^{\circ} \mathrm{C}$. It should be taken into consideration though, that in landscape offices not all occupants commute the same way (private car, public transportation, bicycle or on foot) and they do not all arrive at the office at the same time. This means that any given room temperature control might not be ideal for all occupants. However, it would be more appropriate in educational and public service buildings, where the arrival times of all building occupants are identical. 
Rijal et al. investigated 11 office buildings in Japan for more than a year and developed an equation for buildings in heating, cooling and free-run mode[40]. Figure 12 shows the comparison between the results from their equation for the cooling mode with the current experimental data. The responses for the first questionnaire are presented separately because the participants had higher metabolic rate at that time. It can be seen that the experimental responses of the second questionnaire and onwards are very close to the results extracted from equation developed by Rijal et al., while the responses of the first questionnaire differ substantially. Therefore, when the metabolic rate of the responses from the current experiment was similar to that of the field study, the two sets of subjects' responses almost coincide, in spite the difference of the season (summer during the field study compare to spring during the current experiment). This shows that the dominant factor that affected the subject's thermal perception was not the season or the outdoor conditions during the experiment execution, but the high metabolic rate that the subjects had while filling the first questionnaire.

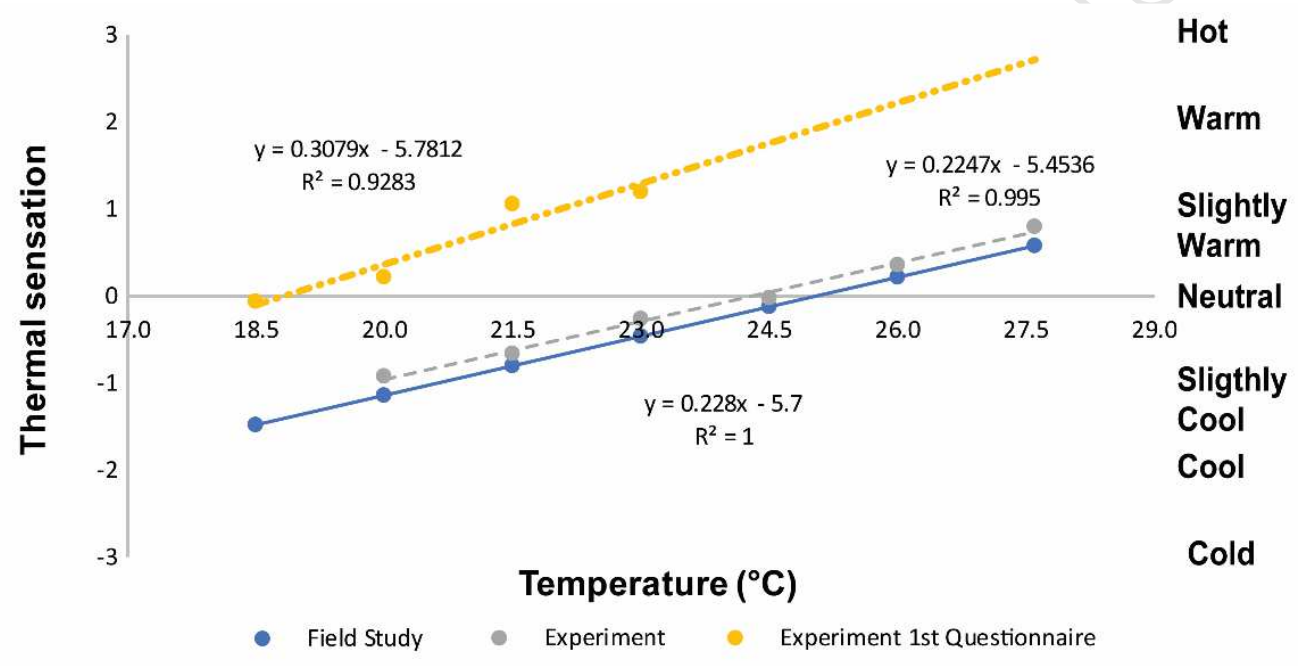

Figure 12: Thermal sensation comparison between current study results with field study results

While there is a seasonal effect on the preferred room temperature level, the relative effect of an increased activity in the morning on the decrease preferred room temperature in the morning is minor. There is some effect as the acceptable change in room temperature for an increased activity level will depend on the clothing level. At a lower clothing insulation, the acceptable decrease in room temperature for an increased activity level will be less than for a heavier clothing. In the present study the authors focused on one level of clothing ( 0.5 clo $)$ considered typical for summer clothing in a temperate climate.

The temperature ranges suggested by the European standard EN 15251 [27] for office buildings assume a metabolic rate of 1.2 met, which is typical for sedentary activity. The authors believe that similar findings would be observed for a 
person with elevated metabolic rate entering an office building, independent of the season, the geographical location or climate conditions, due to the difference in the metabolic rate. This naturally requires further investigation.

For Figure 9 and Figure 10, the PMV - PPD values were calculated based on the program designated by Appendix B of ASHRAE Standard 55 [28]. For the metabolic rate, the ISO Standard 8996 (ISO 2004) was applied, using the heart rate measured during the experiment. In some cases, the wireless connection between the sensor and the receiver failed, resulting in unrealistic values of heart rate. Figure 13 shows an example of such a session, where the heart rate of Participant 1 exceeded 160 heart beats at a time when the subject was sitting at a desk performing office work. This resulted in a metabolic rate of five or six met during the walking phase and up to three met during their stay in the office-chamber. In those cases, the metabolic rate was set by the authors to 2 met during the walking phase and when responding to the first questionnaire, and to 1 met during the rest of their stay in the chamber. These values of metabolic rate were taken from Table A.2 of the ISO Standard 8996 [41].

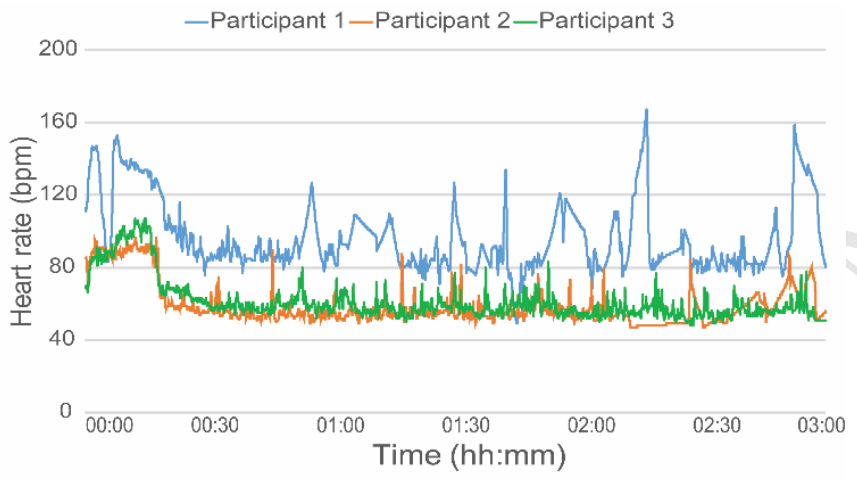

Figure 13: Example of heart rate measured during an experimental session

\section{Conclusions}

The present study examined whether building occupants with slightly elevated metabolic rate due to commuting on foot may accept a room temperature below the comfort range for sedentary activity in the morning. This was studied in an experiment with 25 young people, male and female, exposed to four different conditions. It was concluded that

- No significant differences were observed between the subjective responses of male and female participants

- Due to the increased metabolic rate from walking, lower room temperature than are suggested by EN Standard 15251 were reported as acceptable at the beginning of the occupancy period.

- The impact of the physical exercise had disappeared after approximately 30 minutes 
- Although the conditions in this experiment were transient (an increasing temperature ramp of $1.5 \mathrm{~K} / 0.5 \mathrm{~h}$ ), the results in the neutral zone followed Fanger's model quite closely, although his model was developed from data obtained in steady-state exposures

- In countries where most people commute on foot or by bike, the room air temperature at the beginning of the occupancy period could be $20^{\circ} \mathrm{C}-21.5^{\circ} \mathrm{C}$, namely lower than EN Standard 15251 suggests. It should then increase steadily at a rate of $1.5 \mathrm{~K} / 0.5 \mathrm{~h}$ to reach the comfort range of $23^{\circ} \mathrm{C}-26^{\circ} \mathrm{C}$.

These results could be used by researchers examining thermal comfort or energy use in office buildings and could be taken into consideration in international standards for the indoor environment or the operation of HVAC equipment.

\section{Acknowledgements}

The experiment was funded by the International Centre for Indoor Environment and Energy (ICIEE) and the Nordic Built Project "Low Temperature Heating and High Temperature Cooling in Refurbishment and New Construction of Buildings". The authors would like to thank Nico Henrik Ziersen and Peter Slotved Simonsen for their contribution to the preparation of the experiment.

\section{Reference}

[1] ISO, ISO 7730:2005 Ergonomics of the thermal environment-Analytical determination and interpretation of thermal comfort using calculation of the PMV and PPD indices and local thermal comfort criteria. 2005.

[2] L. Lan, P. Wargocki, and Z. Lian, "Quantitative measurement of productivity loss due to thermal discomfort," Energy Build., vol. 43, no. 5, pp. 1057-1062, 2011.

[3] L. Lan, P. Wargocki, and Z. Lian, "Thermal effects on human performance in office environment measured by integrating task speed and accuracy," Appl. Ergon., vol. 45, no. 3, pp. 490-495, 2014.

[4] P. Wargocki and D. P. Wyon, "Ten questions concerning thermal and indoor air quality effects on the performance of of fi ce work and schoolwork," Build. Environ., vol. 112, pp. 359-366, 2017.

[5] D. P. Wyon and P. Wargocki, "Room temperature effects on office work," in Creating the Productive Workplace, 2006, pp. 181-192.

[6] L. Fang, D. P. Wyon, G. Clausen, and P. O. Fanger, "Impact of indoor air temperature and humidity in an office on perceived air quality, SBS symptoms and performance,” Indoor Air J., vol. 14, no. 7, pp. 74-81, 2004.

[7] J. Kolarik, J. Toftum, B. W. Olesen, and A. Shitzer, “Occupant Responses and Office Work Performance in 
Environments with Moderately Drifting Operative Temperatures (RP-1269)," HVAC\&R Res., vol. 15, no. 5, pp. 931-960, 2009.

[8] M. J. Mendell et al., "Enhanced particle filtration in a non-problem office environment: Preliminary results from a double-blind crossover intervention study," Am. J. Ind. Med., vol. 36, no. 1, pp. 55-57, 1999.

[9] A. Melikov, B. Yordanova, L. Bozkhov, V. Zboril, and R. Kosonen, "Human response to thermal environment in rooms with chilled beams," Proc. Clima 2007 WellBeing Indoors, 2007.

[10] M. Dalewski, A. K. Melikov, and M. Vesely, "Performance of ductless personalized ventilation in conjunction with displacement ventilation: Physical environment and human response,” Build. Environ., vol. 81, pp. 354364, 2014.

[11] Z. Dimitrov and A. Krikor, "Thermal Conditions in a Simulated Office Environment with Convective and Radiant Cooling Systems Ventilation and Energy Conservation in Buildings Publication date : World Congress and the 8th International Conference on Indoor Air Quality, Ventilation an,” 2013.

[12] A. Lipczynska, J. Kaczmarczyk, B. Marcol, W. Kierat, and A. K. Melikov, "Human Response to Personalized Ventilation Combined with Chilled Ceiling,” Proc. 13th Int. Conf. Air Distrib. Rooms, pp. 1-7, 2014.

[13] T. Arghand et al., "Individually controlled localized chilled beam in conjunction with chilled ceiling: Part 2 Human response,” Proc. Indoor Air 2016 Publ., 2016.

[14] Q. Jin, A. Simone, B. W. Olesen, S. K. M. Holmberg, and E. Bourdakis, "Laboratory study of subjective perceptions to low temperature heating systems with exhaust ventilation in Nordic countries," Sci. Technol. Built Environ., vol. 0, no. 0, pp. 1-12, 2017.

[15] A. P. Gagge, J. A. J. Stolwijk, and J. D. Hardy, “Comfort and thermal sensations and associated physiological responses at various ambient temperatures," Environ. Res., vol. 1, no. 1, pp. 1-20, 1967.

[16] E. Arens, H. Zhang, and C. Huizenga, "Partial- and whole-body thermal sensation and comfort - Part I: Uniform environmental conditions,” J. Therm. Biol., vol. 31, no. 1-2 SPEC. ISS., pp. 53-59, 2006.

[17] H. Zhang, C. Huizenga, E. Arens, and D. Wang, “Thermal sensation and comfort in transient non-uniform thermal environments," Eur. J. Appl. Physiol., vol. 92, no. 6, pp. 728-733, 2004.

[18] H. Zhang, E. Arens, C. Huizenga, and T. Han, "Thermal sensation and comfort models for non-uniform and transient environments, Part I: Local sensation of individual body parts," Build. Environ., vol. 45, no. 2, pp. 380-388, 2010.

[19] H. Zhang, E. Arens, C. Huizenga, and T. Han, "Thermal sensation and comfort models for non-uniform and transient environments, part II: Local comfort of individual body parts,” Build. Environ., vol. 45, no. 2, pp. 
389-398, 2010.

[20] H. Zhang, E. Arens, C. Huizenga, and T. Han, "Thermal sensation and comfort models for non-uniform and transient environments, part III: Whole-body sensation and comfort,” Build. Environ., vol. 45, no. 2, pp. 399410, 2010.

[21] C. Huizenga, H. Zhang, E. Arens, and D. Wang, "Skin and core temperature response to partial- and wholebody heating and cooling,” J. Therm. Biol., vol. 29, no. 7-8 SPEC. ISS., pp. 549-558, 2004.

[22] E. Arens, H. Zhang, and C. Huizenga, "Partial- and whole-body thermal sensation and comfort-Part II: Nonuniform environmental conditions," J. Therm. Biol., vol. 31, no. 1-2, pp. 60-66, 2006.

[23] I. D. Griffiths and D. A. McIntyre, "Sensitivity to Temporal Variations in Thermal Conditions," Ergonomics, vol. 17 , no. 4, pp. 499-507, 1974.

[24] T. Goto, J. Toftum, R. de Dear, and P. O. Fanger, “Thermal sensation and thermophysiological responses to metabolic step-changes,” Int. J. Biometeorol., vol. 50, no. 5, pp. 323-332, 2006.

[25] D. A. McIntyre and R. R. Gonzalez, "Man's Thermal Sensitivity During Temperature Changes at Two Levels of Clothing Insulation and Activity,” ASHRAE Trans., vol. 82, no. 2, pp. 219-233, 1976.

[26] J. L. M. Hensen, "Literature Review on Thermal Comfort in Transient Conditions," vol. 25, no. 4, pp. 309-316, 1990.

[27] EN, EN 15251:2007 Indoor environment input parameters for design and assessment of energy performance of buildings adressing indoor air quality, thermal environment, lighting and acoustics. 2007.

[28] ASHRAE, ASHRAE Standard 55: Thermal Environmental Conditions for Human Occupancy. 2013.

[29] B. Moujalled, R. Cantin, and G. Guarracino, "Adaptive thermal comfort evaluation in a field study," Int. Conf. “Passive Low Energy Cool. Built Environ., no. May, pp. 225-230, 2005.

[30] R. De Dear, J. Kim, C. Candido, and M. Deuble, “Adaptive thermal comfort in australian school classrooms,” Build. Res. Inf., vol. 43, no. 3, pp. 383-398, 2015.

[31] S. A. Damiati, S. A. Zaki, H. B. Rijal, and S. Wonorahardjo, "Field study on adaptive thermal comfort in office buildings in Malaysia, Indonesia, Singapore, and Japan during hot and humid season,” Build. Environ., vol. 109, pp. 208-223, 2016.

[32] J. Liu, R. Yao, and R. McCloy, "A method to weight three categories of adaptive thermal comfort," Energy Build., vol. 47, pp. 312-320, 2012.

[33] N. Artmann, H. Manz, and P. K. Heiselberg, "Potential for passive cooling of buildings by night-time ventilation in present and future climates in Europe," 23rd Int. Conf. Passiv. Low Energy Archit., p. 6, 2006. 
[34] S. P. Corgnati and A. Kindinis, "Thermal mass activation by hollow core slab coupled with night ventilation to reduce summer cooling loads," Build. Environ., vol. 42, no. 9, pp. 3285-3297, 2007.

[35] J. Kolarik and B. W. Olesen, "Energy Use and Thermal Comfort in a Building with Thermo Active Building System (TABS)," in Indoor Climate of Buildings 2007, 2007.

[36] J. Kolarik, J. Toftum, B. W. Olesen, and K. L. Jensen, "Simulation of energy use, human thermal comfort and office work performance in buildings with moderately drifting operative temperatures," Energy Build., vol. 43, no. 11 , pp. 2988-2997, 2011.

[37] E. Bourdakis, T. Q. Péan, L. Gennari, and B. W. Olesen, "Daytime space cooling with phase change material ceiling panels discharged using rooftop photovoltaic/thermal panels and night-time ventilation," Sci. Technol. Built Environ., vol. 4731, no. June, 2016.

[38] P. Kjerulf-Jensen, Y. Nishi, H. Graichen, and R. Rascati, “A test chamber design for investigating man’s thermal comfort and physiological response,” ASHRAE Trans., vol. 82, no. 1, pp. 73-82, 1975.

[39] P. O. Fanger, Thermal comfort. Copenhagen, Denmark: Danish Technical Press, 1970.

[40] H. B. Rijal, M. A. Humphreys, and J. F. Nicol, "Towards an adaptive model for thermal comfort in Japanese offices," Build. Res. Inf., vol. 45, no. 7, pp. 717-729, 2017.

[41] ISO, ISO 8996: Ergonomics of the thermal environment-Determination of the metabolic rate. 2004. 


\section{Highlights}

- No significant differences between the responses of male and female participants

- Lower room temperature than what suggested by standards reported as acceptable

- The impact of the physical exercise had disappeared after approximately 30 minutes

- The results in the neutral zone followed Fanger's model quite closely

- The room temperature at the beginning of the occupancy period could be $20^{\circ} \mathrm{C}-21.5^{\circ} \mathrm{C}$ 